OPEN ACCESS

Edited by:

Fernando Cendes,

State University of Campinas, Brazil

Reviewed by:

Lanping Xu,

Peking University People's

Hospital, China

Patrizia Pulitano,

Sapienza University of Rome, Italy

*Correspondence:

Sujun Gao

sjgao@jlu.edu.cn

Specialty section:

This article was submitted to

Epilepsy,

a section of the journal

Frontiers in Neurology

Received: 03 March 2021

Accepted: 17 June 2021

Published: 16 July 2021

Citation:

Wang Z, Zhao M and Gao S (2021) Epileptic Seizures After Allogeneic

Hematopoietic Stem Cell Transplantation.

Front. Neurol. 12:675756

doi: 10.3389/fneur.2021.675756

\section{Epileptic Seizures After Allogeneic Hematopoietic Stem Cell Transplantation}

\author{
Zhuo Wang ${ }^{1}$, Munan Zhao ${ }^{2}$ and Sujun Gao ${ }^{1 *}$ \\ ${ }^{1}$ Department of Hematology, The First Hospital of Jilin University, Changchun, China, ${ }^{2}$ Department of Oncology, The First \\ Hospital of Jilin University, Changchun, China
}

Technique in allogeneic hematopoietic stem cell transplantation has greatly advanced over the past decades, which has led to an increase in the number of patients receiving transplantation, but the complex procedure places these transplant recipients at high risk of a large spectrum of complications including neurologic involvement. As a common manifestation of neurological disorders, epileptic seizures after transplantation have been of great concern to clinicians because it seriously affects the survival rate and living quality of those recipients. The aim of this review is to elucidate the incidence of seizures after allogeneic hematopoietic stem cell transplantation, and to further summarize in detail its etiologies, possible mechanisms, clinical manifestations, therapeutic schedule, and prognosis, hoping to improve doctors' understandings of concurrent seizures following transplantation, so they can prevent, process, and eventually improve the survival and outlook for patients in a timely manner and correctly.

Keywords: allogeneic hematopoietic stem cell transplantation, complications, epileptic seizures, neurotoxicity, status epilepticus

\section{INTRODUCTION}

Allogeneic hematopoietic stem cell transplantation (allo-HSCT) has been considered the only curative treatment for some malignant hematological diseases, and the long-term survival rate of patients with these hemopathies improved dramatically because of the continuous improvements and maturation in bone marrow transplant procedures and supportive care (1). But as a high-risk therapy, HSCT is still associated with a series of complications including the involvement of the central nervous system (CNS). Studies have reported an incidence of neurologic complications after HSCT ranging from 6.6 to $70 \%(2-8)$, such a wide span may be explained by the heterogeneity of study populations and extensive differences in definitions of CNS complications. An epileptic seizure is one of the most common symptoms of neurological disorders, they can manifest as strange sensations, emotions, and behaviors, or sometimes convulsions, muscle spasms, and loss of consciousness, eventually leading to serious impairments of normal CNS function and even death. Several clinical studies have indicated that seizures are a relatively uncommon but life-threatening symptom of neurologic complication after alloHSCT, with incidence ranging from 1.6 to $15.4 \%(4,9-12)$, and those transplanted recipients with seizures often have poor prognosis and lower quality of life, so they should be paid more attention to by clinicians. Unfortunately, there is limited literature focusing on this subject and unified therapeutic approaches are still lacking. Herein, we aim to provide a comprehensive summary about the etiologies (Table 1) and possible underlying mechanisms (Figure 1) of seizures after allo-HSCT, its clinical features, treatment, and prognosis are also described; a better 
understanding of these basic aspects is of paramount importance to help doctors prevent related risk factors earlier, treat properly and promptly, and finally improve patients' clinical outcomes.

\section{ETIOLOGIES AND POSSIBLE MECHANISMS OF POST-TRANSPLANT SEIZURES}

\section{Drug-Related Neurotoxicity Chemotherapy}

During the implementation of allo-HSCT, drug-related adverse effects have always been a clinical concern, especially when a convulsive seizure occurs in the early phase of transplantation; medication factor is theoretically the primary consideration. It is known that busulfan $(\mathrm{Bu})$ is frequently employed in conditioning regimens for patients undergoing HSCT, highdose $\mathrm{Bu}$ can freely penetrate the blood-brain barrier (BBB), leading to an almost similar level of $\mathrm{Bu}$ concentration in both CNS and plasma (13), and it performs its neurotoxic effects through damaging neurons, so adjustment of administration dosage by monitoring $\mathrm{Bu}$ concentration is recommended in clinic (14). Previous studies have reported a seizure rate of $\sim 10 \%$ (range 1.8-40\%) after $\mathrm{Bu}$ usage in adults when there were no prophylactic anticonvulsants $(15,16)$, furthermore, up to $60 \%$ of patients may present with an abnormal electroencephalogram (EEG) even without significant seizure symptoms $(17,18)$. This phenomenon further confirms its neurotoxic effects. Under this circumstance, phenytoin sodium has been routinely utilized to prevent busulfan-induced seizures (BIS) in clinical practice for years though there still exists a frequency of $0-5.5 \%$ in the incidence of seizures $(16,19,20)$. Given the facts that phenytoin sodium has the disadvantages of being a strong inducer of cytochrome P450 (CYP) hepatic enzyme, which influences the metabolism of cyclophosphamide in the conditioning schedule of HSCT recipients, together with its narrow therapeutic window and the advent of new antileptic drugs, new research efforts in some SCT centers have shifted to using alternatives as prophylaxis against BIS, such as benzodiazepines, valproate, etc. $(16,21-24)$. Levetiracetam stands out because it fulfills many of the properties of an ideal prophylactic agent, for example, it has $\sim 100 \%$ bioavailability, it lacks a significant drug-drug interaction, and can be rapidly loaded to effective doses, what is more, it shares a similar outcome with phenytoin in seizure prevention and overall effects $(19,21,22,25)$. Chaguaceda et al. (26) have suggested that the optimal dose of oral levetiracetam to prevent BIS in adults seemed to be $1,000 \mathrm{mg}$ every $12 \mathrm{~h}$, starting $12 \mathrm{~h}$ before the administration of iv $\mathrm{Bu}$ until $48 \mathrm{~h}$ after the last dose. In the future, more prospective studies with larger populations are necessary to validate its efficacy, safety, and appropriate dosage to act as a first-line anticonvulsant for BIS prevention.

\section{Immunosuppressants}

Calcineurin inhibitors (CNIs) are a class of widely used drugs to prevent graft vs. host disease (GVHD) and its sequelae after HSCT. Cyclosporin A (CsA) and tacrolimus (TAC) are mainly
TABLE 1 | Etiologies of seizures following allo-HSCT.

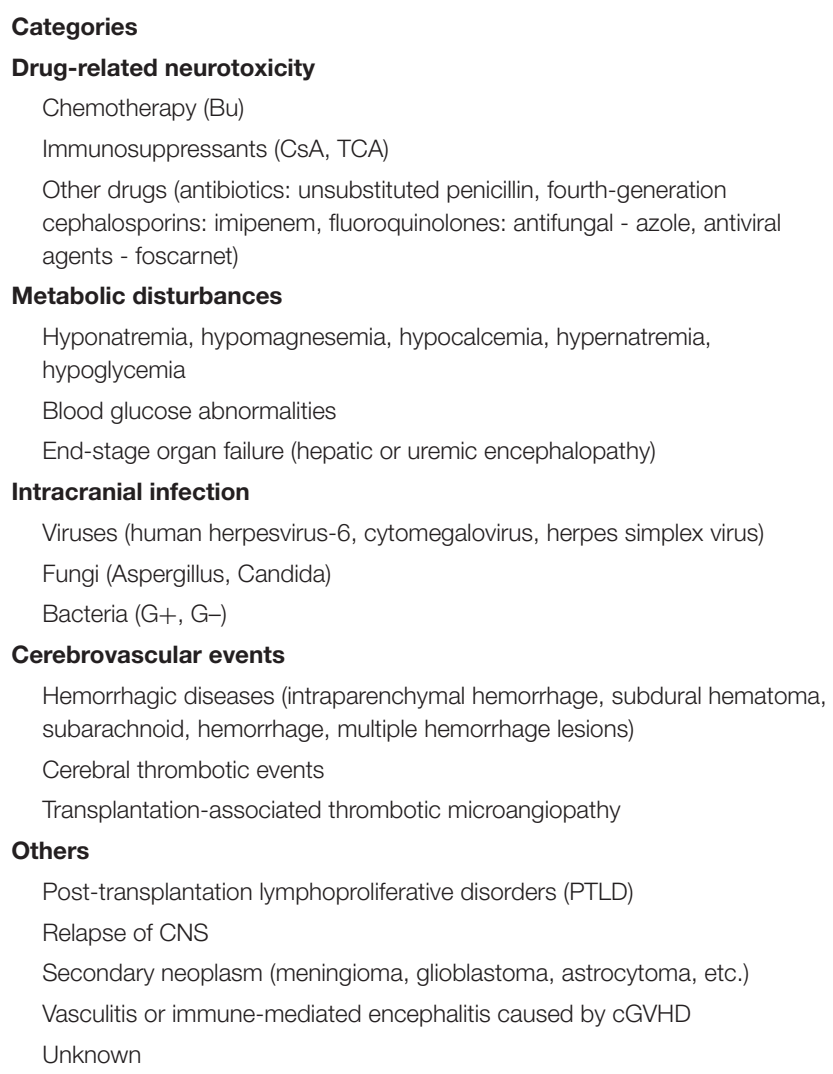

included, they exert immunosuppressive actions by binding to immunophilins to inhibit the calcineurin-mediated calciumdependent signaling pathways that mediate the formation of interleukin-2 and T-lymphocyte activation (27). Although many patients benefit from them, neurotoxicities caused by these agents have remained serious, a seizure is one of the severe manifestations which cannot be ignored. Based upon a retrospective study of over 1461 recipients of HSCT by Zhang et al. (10), more than $40 \%$ of seizures are associated with drug application, especially the usage of immunosuppressants which are listed at the top of reasons for epileptic seizures; this result is consistent with other similar investigations (12, 28). Nevertheless, the occurrence of seizures is not positively correlated with the blood concentration of CsA, this might be attributable to the inter-individual variation in the metabolism of CsA (29).

Previous reports have indicated that both CsA and TAC enhance the permeability of the blood-brain barrier (BBB) by damaging tight junctions directly, inducing apoptosis of brain capillary endothelial cells (30), and decreasing P-glycoprotein's efflux pump function $(27,31)$. In addition, CsA exposure can increase nitric oxide (NO) production in brain endothelial and astroglial cells, further mediating endothelial injury and impairment of $\mathrm{BBB}$ function $(32,33)$. But the underlying mechanism through which CNIs cause convulsions after penetrating the BBB has not yet been fully elucidated, although 


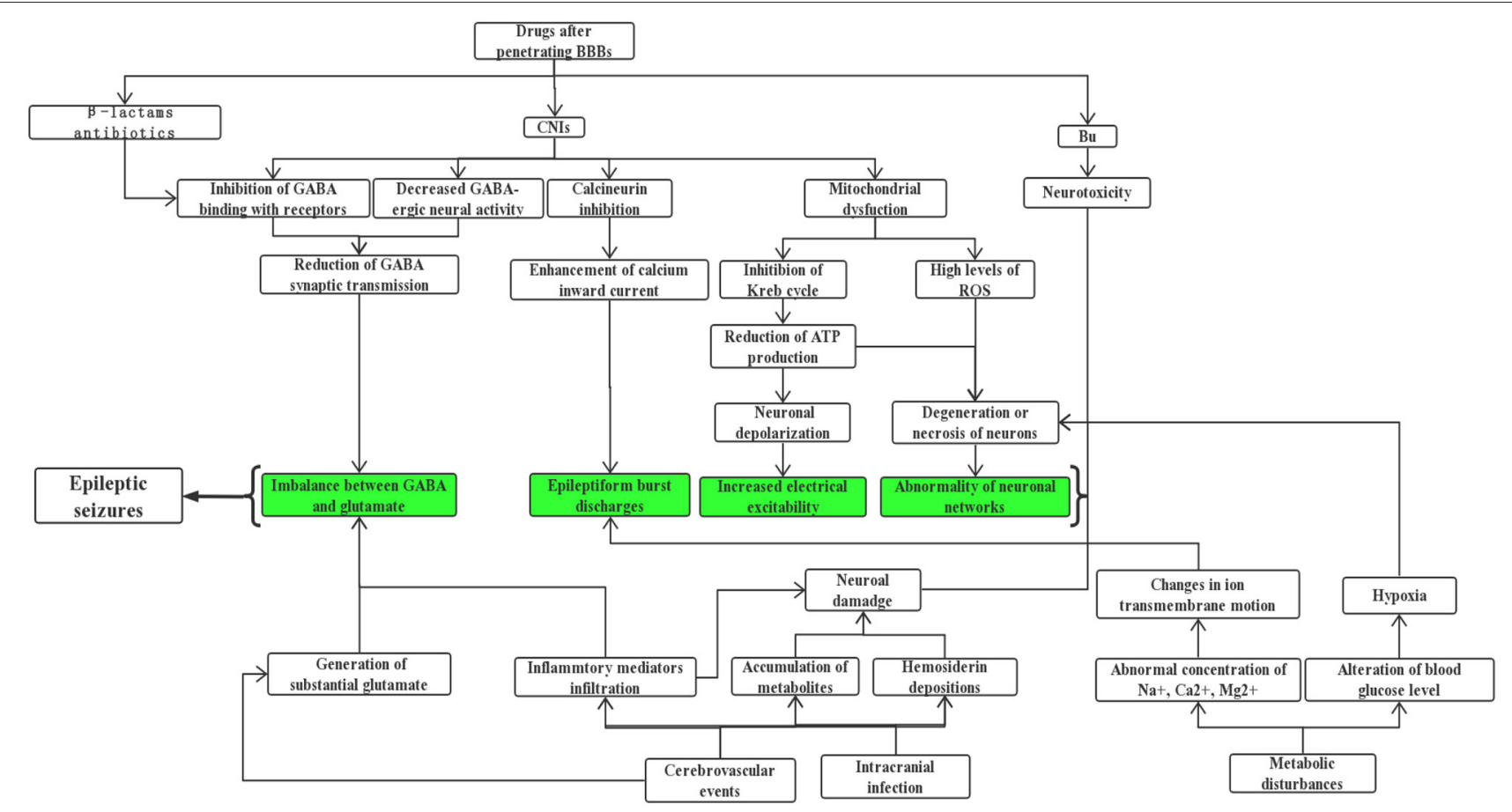

FIGURE 1 | The main mechanisms of seizures after allo-HSCT.

several explanations have been proposed: (1) There is evidence $(34,35)$ showing that CsA can decrease gamma aminobutyric acid ( $\gamma$-GABA) neural activity. Meanwhile, it can inhibit GABA from binding to its receptors, eventually influencing synaptic transmission of this inhibitory neurotransmitter and breaking down the balance with those excitatory ones. (2) Klawitter et al. (36) drew the conclusion that CsA gave rise to mitochondrial disorder, mainly reflecting in the inhibition of the Krebs cycle and reduction of adenosine triphosphate (ATP). In this case, nerve cells are prone to depolarize and discharge, which lays the foundation of seizures. Besides, a derailment of mitochondrial oxidative phosphorylation probably results in the release of a high level of reactive oxygen species (ROS) $(37,38)$, which can induce loss of neural viability and a drop in the number of neurons; these changes are of great value in increasing susceptibility to seizures. (3) It is well-recognized that calcineurin is widely distributed in multiple sites of the brain, for instance, the cerebral cortex, striatum, cerebellum, substantia nigra, and hippocampus, where it regulates the activity of ion channels, synaptic plasticity, and even neurotransmitter release $(27,39)$. Inhibition of its critical roles by CNIs brings about ion channel dysfunction, especially the enhancement of calcium inward current, eliciting epileptiform burst discharges $(40,41)$. (4) The breakdown of the BBB can further lead to vasogenic edema, with a predilection for the posterior cerebral white matter, which matches the earliest pathogenesis of posterior reversible encephalopathy syndrome (PRES). This disease is characterized by a series of neurologic symptoms, ranging from headache, seizures, confusion, visual disturbances, and so on, of which seizures occur in more than $70 \%$ of patients who suffered from PRES $(6,31)$. From the perspective of clinical electrophysiology, Grioni et al. (42) even regarded it as a posterior unilateral reversible epileptic disorder in essence. If there is prolonged exposure to CNIs, cytotoxic edema resulting from mitochondrial dysfunction and reduced NO production exists simultaneously, this maybe an early indication of irreversible damage (31, $33,43)$. Besides, other investigators believed that CNI-induced convulsions might be associated with gene polymorphism and other factors $(29,44-46)$. Interestingly, there are studies reporting that CNIs may behave as neuroprotective agents in animal models of epilepsy $(47,48)$, which contradicts the current understanding, so additional investigations are needed to clarify the key influential factors of determining whether it exerts a toxic or protective effect.

\section{Other Drugs}

Prophylactic or therapeutic usage of certain antibiotics in both pre and post transplantation periods can also trigger epileptic seizures or status epilepticus (SE) despite a relatively rare incidence. It has been documented in reviews (49-51) that a high dosage of $\beta$-lactams has epileptogenic potential, which is most commonly found in patients prescribed with unsubstituted penicillin, fourth-generation cephalosporins as well as carbapenems (mainly imipenem). These antimicrobials lower the seizure threshold by competitive antagonism of GABA receptors. If recipients are diagnosed with comorbidities such as renal insufficiency, brain lesions, or pre-existing epilepsy, they are more prone to seizures. With the similar 
mechanism to $\beta$-lactams, fluoroquinolones are another category of proconvulsant antibiotic agents $(50,52,53)$. But evidence is only limited to case reports, possibly explained by its lower capability to cross the BBB. As we know, hospitalization medication use of a single patient receiving HSCT is complicated, for this reason, establishing causation between antibiotics and seizures is often confounded by various contributors. Anyway, clinicians should be vigilant when they select antibiotics and define the optimal dosage, if necessary, drug adjustment on an individual basis by closely monitoring of serum levels may help, especially for those predisposed subjects mentioned above. Also, it was reported that foscarnet, an antiviral option in immunocompromised patients, has the risk of causing seizure activity (54). It is noteworthy that drug-drug interaction during the process of HSCT should not be overlooked by prescribers as this phenomenon is related to increasing occurrence of adverse consequences $(55,56)$. Take the combination of CNIs and azole antifungals for an example, the latter obviously increases the plasma concentration of CsA and the incidence of epileptiform seizures due to potent inhibition of CYP 3A4 (55-57).

\section{Metabolic Disturbances}

For new-onset symptomatic seizures following HSCT, common metabolic disorders (i.e., hyponatremia, hypomagnesemia, hypocalcemia, hypernatremia, and hypoglycemia, etc.) should be excluded and promptly corrected (58), of which the first type usually occurs the most $(10,59)$. Seizures are more likely to present in cases experiencing severe and rapidly evolving electrolyte imbalances (60), alterations of serum sodium, or osmolality that exerts direct and indirect effects on neuronal discharge mainly by destroying the state of electrical excitability maintained by an ion gradient across cellular membranes. Likewise, patients who suffer from hypomagnesemia and hypocalcemia can develop CNS irritability clinically manifesting with seizures as well $(60,61)$. As for the pathogenesis of seizures caused by abnormalities in the blood-glucose level, it may be related to neuronal degeneration on account of hypoxia. No matter what kind of disturbance, seizures can be controlled well without sequelae after the underlying reversible factors are properly corrected. In addition, convulsions may be a sole present symptom or one of the performances when CNS involvement secondary to end-stage organ failure after HSCT happens $(10,59,62)$. For instance, fulminant hepatitis, liver aGVHD, and hepatic vein occlusion in the context of allografting can result in hepatic encephalopathy and transplantation-related thrombotic microangiopathy/hemolytic-uremic syndrome. CNI nephrotoxicity can cause irreversible kidney injury, and then accumulated toxins in the body cannot be cleared in time, thus resulting in uremic encephalopathy. Whereas such syndromes are mainly dominated by inhibitory neurologic behaviors, the level of consciousness ranges from coma to drowsiness, and seizures are infrequent (62).

\section{Intracranial Infection}

Vascular wall or mucosal damage caused by intensive chemotherapy or total body irradiation, coupled with high doses of immunosuppressive drugs pose a risk for CNS infection in patients undergoing allo-HSCT (63-65). According to changes in their immune status during transplant practice, three phases can be divided: the initial ( $<30$ days after HSCT), intermediate (30100 days after HSCT), and late ( $>100$ days after HSCT) periods. Intracranial infection can occur at these three distinct time points and predominant microorganisms in each phase differ $(64,66)$. What is more, it takes time for these immunocompromised patients to reconstitute a functioning immune system, making them more susceptible to opportunistic infection s (67). In contrast to HLA-matched sibling transplantation, patients receiving umbilical cord blood transplantation are more likely to develop a CNS infection (1.7 vs. $8.2 \% ; P<0.001$ ) (68), probably because of a delayed hematologic and immune recovery. The spectrum of major causative pathogenic agents is as follows: fungi such as Aspergillus and Candida, viruses like human herpesvirus-6 (HHV-6), cytomegalovirus, herpes simplex virus, protozoal infection particularly toxoplasma, and G+/G- bacteria $(64,66,68-71)$. Convulsions are a common finding in neurologic infections manifesting as meningitis, encephalitis, or brain abscesses, but are of an extremely nonspecific nature. In a retrospective analysis of 1,461 cases with allo-HSCT, infections of the CNS were reported in 14 (17.7\%) out of 79 patients with seizures (10); the most frequent culprits were fungi and virus, followed by toxoplasma and bacteria. Most CNS viral infections post-HSCT result from a secondary reactivation of a latent pathogen (72), but observations by Santoro et al. (73) indicated it was primary infection rather than reactivation that was associated with subsequent seizures, due to the phenomenon that lower cerebrospinal fluid (CSF) viral load may display a higher likelihood of seizures in pediatric patients infected with HHV6 after transplant; further studies are needed to verify. The above infections can directly damage brain parenchyma and induce seizures $(10,59,64)$. In addition, recent studies have demonstrated that inflammatory mediators such as interleukin-1 beta can cause hippocampal damage and imbalance between GABA and glutamate, thus participating in the generation of epilepsy $(74,75)$. Hence, it is speculated that when post-transplant neurologic infections occur, on one hand, the pathogens may cause local hemorrhage by invading microvessels in the brain, and the accumulation of metabolites can lead to the degeneration or necrosis of neurons, on the other hand, the process of inflammatory cell infiltration and release of various cytokines in the damaged brain regions may also be involved in the epileptogenic effects.

\section{Cerebrovascular Events}

In the post-HSCT setting, the frequency of cerebrovascular diseases including ischemic and hemorrhagic strokes ranges from 2.9 to $4.6 \%(9,76,77)$, of which intracranial hemorrhage (ICH) is more frequent than brain infractions in some literature $(4,69)$, while other findings described a similar incidence of hemorrhagic and thrombotic complications $(9,77)$. Despite a fortunate lower percentage, it is often correlated with dismal prognosis and high mortality. In a retrospective report $(n=2,169)$ of patients undergoing alloSCT, ICH was seen in a total of 32 cases (1.5\%), of which $82.9 \%$ of the cases were intraparenchymal hemorrhage (IPH), 5.7\% of cases were subdural hematoma (SDH), and 8.6\% 
of cases were multiple hemorrhage lesions (78). Another study conducted by Najima et al. (79) found that 21 of 622 (3.4\%) allo-HSCT recipients suffered ICH over a 20 -year period. The rates of $\mathrm{IPH}, \mathrm{SDH}$, and subarachnoid hemorrhage $(\mathrm{SAH})$ were $71.4,19$, and $14.3 \%$, respectively. These phenomena are distinct from previous concepts that $\mathrm{SDH}$ appears most often and rarely causes death $(69,70)$. Most evidence supports the fact that the median time of vascular accidents is around day 100 after transplant (77-80). The common risk factors for developing ICH following allo-HSCT are systemic infections, lower platelet count or fibrinogen levels, and grade III-IV aGVHD, sometimes it is futile even if adequate prophylactic platelets are transfused. In contrast, the occurrence of cerebral thrombotic events may be related to an aberrant coagulative profile or thromboembolism from endocarditis or atrial fibrillation. The clinical picture of cerebrovascular events is usually characterized by headache, convulsions, disturbance of consciousness, paralysis, and so on. It is reported that more than $40 \%$ of patients who received HSCT had seizures as part of the clinical presentation of their cerebrovascular diseases $(76,78)$. The emergence of seizures in the acute stage of cerebrovascular events may originate from a lower threshold for depolarization secondary to substantial glutamate, beyond this, the stimulatory effects of the cortex by blood metabolites and hemosiderin depositions also work. In the later phase, a permanent brain dysfunction covering gliosis, scars, or loss of neurons may form, bringing about abnormal neuronal networks and increased neuronal excitability $(81,82)$. It is also worth noting that transplantation-associated thrombotic microangiopathy (TA-TMA), a serious complication of alloHSCT with a mortality rate higher than $70 \%$ even after targeted treatment $(83,84)$, affects multiple systems with widespread endothelial injury and complement activation. Once the CNS is involved, it may manifest as headaches, convulsions, confusion, or hallucinations (84), but there is a paucity of information for the precise incidence of seizures.

\section{Others}

Patients may suffer from various forms of tumors after HSCT, more specifically, the relapse of the CNS, post-transplantation lymphoproliferative disorders (PTLD), and secondary neoplasm. Oshima et al. (85) reported that the cumulative incidence of CNS recurrence after HSCT in leukemia patients was $2.3 \%$, which was one of the important reasons for the failure of transplantation. For PTLD, upon most occasions, it is related to Epstein-Barr virus reactivation and featured by unregulated proliferation of B-lymphocytes. CNS-PTLD can be either disseminated PTLD with CNS involvement or isolated CNS-PTLD, a scarce but lifethreatening complication (86). Moreover, patients who received high doses of TBI seem to be particularly liable to develop a new cancer within 10 years or more, such as meningioma, glioblastoma, and astrocytoma, etc. The clinical symptoms of sufferers with all these three conditions are non-specific and consist of seizures, altered mental status, or focal neurological deficits. Given their rarity in clinic, few controlled studies have evaluated the rate and time course of a certain manifestation like convulsions. Last but not the least, neurological presentations of chronic GVHD such as vasculitis and immune-mediated encephalitis, albeit less likely, are another element causing epileptic seizures $(87,88)$. Their pathological hallmarks are the infiltration of donor-derived monocytes and CD3+CD8+ cytotoxic $\mathrm{T}$ cells into the brain parenchyma (89), a striking histological homophyly to pathological specimens after surgical resection in patients with temporal lobe epilepsy (90). This finding may provide a clue for some unexplained posttransplant seizures, and of course, further investigation is required.

\section{CLINICAL FEATURES}

In terms of the onset timing of transplantation-related seizures, Zhang et al. (10) have reported that up to $90 \%$ of seizures occur within 1 year after HSCT, especially in the first 100 days, which accounted for more than three-fifths of all transplanted patients with seizures. Only a limited number of patients (3.8\%) had convulsions at the conditioning phase, while seizures caused by CNS relapse generally appeared after the first year. To be more specific, seizures induced by $\mathrm{Bu}$ toxicities typically happen between the second day of $\mathrm{Bu}$ administration and $24 \mathrm{~h}$ following the final dose of Bu owing to its accumulation (16). PRES after HSCT, a clinical neuroradiologic entity with an incidence of 1.1$8.3 \%(6,91-93)$, preferentially presents within the first month $(6,42,94,95)$. Zhang et al. (10) also found that the median interval of seizures is 56 days (range of -6 to +880 ), which is similar to a smaller-sized study conducted for children by Cordelli et al. (12), who documented a median period of 78 days after infusion of stem cells (range $-3 ;+352$ ). From the perspective of the overall frequency, 16 out of 28 transplanted patients with seizures have a single course, and repeated seizure often happen within 7 days after onset (12), only a few cases finally developed refractory epilepsy, which were mostly related to taking CsA orally (96).

After searching the related literature about seizure types, it can be concluded that both generalized and focal seizures have been reported in patients receiving HSCT, and the former is in the majority, especially generalized tonic-clonic seizures (GTCS), but prospective research on this topic is still scarce. Zhang et al. (10) analyzed recipients of allo-HSCT between 2004 and 2010 at their institute and summarized that those who experienced generalized-onset seizures occupied about $65 \%$ of all sorts of attacks, followed by complex partial seizures and simple partial seizures. Some other seizures like partial seizures progressing into grand mal or absence seizures have been documented as well (59). Dating back to etiologies, as most generalized seizures are associated with CNI administration (27, 97), they may be accompanied by some mental and behavioral abnormalities or just occur in isolation, and seizures can be terminated after reducing the dosage, drug discontinuation, or switching to other immunosuppressive drugs. In addition, GTCS is also one of the most common seizure types caused by $\mathrm{Bu}$. When it comes to post-transplanted PRES, occipital lobe seizures and status epilepticus (SE) are the common seizure types described in this syndrome, in particular, SE is most frequently observed in children $(91,98)$. The initial symptoms of the first seizure may only be a tiny twitch or some focal 
signs of non-convulsive manifestation, such as gaze deviation, eye clonus, visual hallucinations, or just changes in mental state. An electroencephalogram (EEG) examination at this time is necessary to confirm diagnosis followed by intervention without delay. Focal seizures are common in patients with local structural alteration in the brain, such as intracranial hemorrhage, encephalitis, and brain abscess, etc. The abnormal discharge of neurons originates from one side of the cerebral hemisphere, which can be manifested as motor and sensory syndromes or simply a minor decreased level of consciousness, some of them probably evolve into generalized convulsions. Univariate and multivariate statistical analysis pointed out that the age of recipient ( $\leq 18$ years), haploidentical transplantation, and aGVHDs are high risk factors for seizures, probably explained by incomplete development of the nervous system in children and the increased dosage of immunosuppressants to prevent GVHD, thereby increasing the vulnerability to infection and drug toxicity (10). However, this result differs from that identified in pediatric HSCT (12), concluding that cord blood stem cell (CBSC) transplantation and non-oncological diseases were the influencing factors for seizures. Diverse transplant procedures and population characteristics of different age groups may give a possible explanation for this phenomenon.

After the attack of the first seizure following allo-HSCT, doctors are advised to expeditiously conduct blood glucose, electrolyte, blood routine examination, inspections of liver, kidney functions, and immunosuppressant concentration measurements to determine the underlying causes, and equally important, prompt adjustment of treatment plans to prevent irreversible damage to the brain. If CNS infection or recurrence is suspected, a lumbar puncture and culture of blood and urine are needed to seek for ancillary evidence. The changes in cerebrospinal fluid during the early stage of cranial infection may be inconspicuous, so a repetitive submittal for inspection is necessary as the disease progresses to find out the relevant pathogen or infiltrated tumor cells. Moreover, imaging examination (computed tomography and magnetic resonance imaging) also provide certain vital references for judging the cause and severity of seizures after $\operatorname{HSCT}(66,86)$. In most cases, a CT scan is the first-line modality despite of a lower sensitivity and detectable rates than MRI, mainly employed to exclude hemorrhagic diseases. For example, a large patch of high signal intensity on T2-weighted and FLAIR is particularly suggestive of CsA neurotoxicity, and the lesions are usually bilateral, symmetrical, and located predominantly in the posterior cerebral white matter, and sometimes is also involved the cortex $(29,98,99)$. If the limbic system including temporal lobe, hippocampus, and amygdala has hyperintense lesions, it may resemble the typical imaging appearances of HHV-6 infection $(66,73,100)$. Another diagnostic tool is EEG, which can assist with the determination of seizure type and therapeutic guidance, especially when patients are in a coma. It is of great significance to discern non-convulsive status epilepticus $(58,97)$. For patients suffering from PRES, whose EEG abnormalities behave like periodic lateralized epileptiform discharges or spike discharges deriving from parieto-occipital or occipital-temporal regions precede neuroradiological changes, an urgent EEG test can aid in earlier diagnosis and management $(12,58,91)$.

\section{THERAPY AND PROGNOSIS}

\section{Etiological Treatment}

In the early stage of convulsions, it is key to accurately decide the causes and eliminate them in time, such as correcting electrolyte derangements, regulating blood glucose, and controlling blood pressure, emergency platelet transfusion, and anti-infection, etc. If a seizure is considered to be induced by CNIs, after weighing long-term efficacy against the risk of rejection, replacing the medication or lowering its dosage may help with the termination of attack. Other generic drugs can be combined or replaced to avoid irreversible brain damage caused by nonimmediate disposal. There were also other promising therapeutic strategies put forward aiming at improving immunosuppressantinduced seizures after organ transplantation $(101,102)$, like lipid supplementation and combinations of CsA with $\mathrm{N}-(30,40-$ dimethoxycinnamonyl) anthranilic acid (3,4-DAA), an agent known to suppress immune response through inducing the apoptosis of activated T cells, but there have been no such reports in CNIs-induced seizures after allo-HSCT. In general, most of these seizures do not require long-term treatment with antiepileptic drugs (AEDs) if only removing reversible incentives. A close observation of signs alone in clinic is required.

\section{Pharmacological Therapy}

The overall goals of treating post-transplanted patients with seizures have been published in a review by Shepard et al. (58), which are in accordance with those who suffer from epilepsy. Besides recognizing and dislodging underlying causes, controlling seizures with AEDs is of great significance. When SE occurs after allo-HSCT, intravenous use of benzodiazepines or midazolam is deemed first-line therapy, if it is not stopped and an intractable SE develops, anesthetics (such as propofol) with anticonvulsive effects can be administrated under the circumstances of essential life support $(12,99)$. Nevertheless, prognosis of these patients is unfavorable and mortality is high. For sufferers of acute repetitive seizures or a single epileptic episode along with potential recurrence risk on EEG and/or cerebral imaging, or even when the underlying epileptogenic cause is uncertain, oral AEDs like levetiracetam or gabapentin should be initiated according to the suspected seizure type $(52,58,103)$, most patients can benefit a lot from them. For example, Cordelli et al. (12) and Zhong et al. (59), respectively, reported that 96.43 and $75 \%$ of recipients had seizure termination after taking anticonvulsants. The total duration of drug therapy is 1-3 months in general (104), a longer time should be ensured for those transplanted candidates with organic lesions. In any case, the principle of selecting appropriate AEDs is trying to avoid those with strong drug interactions, liver enzyme-inducing properties, and potent inhibitory effects to hematopoietic functions. Unfortunately, there is still no definitive guidelines or expert consensus to refer to for such a patient group, so the final therapeutic regimen mostly relies on experience in clinical practice. As mentioned above, levetiracetam is the 
first choice to semeiologically treat concurrent seizures after transplantation because of its favorable features. Surprisingly, Peyrl et al. (105) reported a case of secondary graft failure after HSCT because of treatment-related myelodysplastic syndrome during the period of levetiracetam administration, and believed that levetiracetam was the possible cause. Therefore, studies on the safety profile of levetiracetam remain to be evaluated further in post-transplanted patients with seizure attacks.

\section{Treatment Outcomes}

A retrospective study conducted by Cordelli et al. (12) found that the 5-year overall survival for patients with seizures was statistically lower when compared to those without seizures, which is consistent with the conclusion drawn by Zhang et al. (10). After a follow-up of 1,461 patients with HSCT for 6 years, the transplantation-related cumulative survival rate of recipients experiencing seizures declined dramatically, with 71.4 and $31.1 \%$, respectively. Meanwhile, 42 of 79 patients with epileptiform seizures died, of which 17 patients succumbed to uncontrolled seizures or related causes. Subgroup analysis showed that different reasons for epileptic seizures after HSCT could exert different impacts on survival conditions. For example, the mortality of patients undergoing epileptic seizures caused by intracranial infection and cerebrovascular disease was relatively high and the prognosis was dismal, while PRES seldom had effects on survival, often ending with a good outcome. Another phenomenon worth noting is that patients who showed postoperative SE had a high death rate and great attention should be paid to it in clinic.

\section{CONCLUSIONS AND PERSPECTIVES}

Epileptic seizures in patients of allo-HSCT are not infrequent in clinical practice, increasing attention has been paid to it by

\section{REFERENCES}

1. Horan JT, Logan BR, Agovi-Johnson MA, Lazarus HM, Bacigalupo AA, Ballen KK, et al. Reducing the risk for transplantation-related mortality after allogeneic hematopoietic cell transplantation: how much progress has been made? J Clin Oncol. (2011) 29:805-13. doi: 10.1200/JCO.2010.32.5001

2. Colombo AA, Marchioni E, Diamanti L, Di Matteo AM, Baldanti F, Furione $M$, et al. Neurological complications involving the central nervous system after allogeneic hematopoietic stem cell transplantation during a period of evolution in transplant modalities: a cohort analysis. Transplantation. (2017) 101:616-23. doi: 10.1097/TP.0000000000001257

3. Barba P, Pinana JL, Valcarcel D, Querol L, Martino R, Sureda A, et al. Early and late neurological complications after reduced-intensity conditioning allogeneic stem cell transplantation. Biol Blood Marrow Transplant. (2009) 15:1439-46. doi: 10.1016/j.bbmt.2009.07.013

4. Teive HA, Funke V, Bitencourt MA, de Oliveira MM, Bonfim C, Zanis-Neto J, et al. Neurological complications of hematopoietic stem cell transplantation (HSCT): a retrospective study in a HSCT center in Brazil. Arquivos de neuropsiquiatria. (2008) 66:685-90. doi: 10.1590/S0004-282X2008000500014

5. Bhatt VR, Balasetti V, Jasem JA, Giri S, Armitage JO, Loberiza FR, et al. Central nervous system complications and outcomes after allogeneic hematopoietic stem cell transplantation. Clin Lymph Myeloma Leukemia. (2015) 15:606-11. doi: 10.1016/j.clml.2015.06.004 clinicians due to its poor prognosis. However, research on this issue is still limited up to now. Most studies are retrospective, with some authors including patients with a previous history of epilepsy or existing brain damage when gathering data. Therefore, a further expansion of sample size and targeted prospective studies should be attempted in the future. At the present stage, etiologies of epileptic seizures after transplantation mainly focus on drug-related neurotoxicity, metabolic disorder, cerebrovascular events, intracranial infection, and CNS recurrence. However, sometimes seizures may be the result of the co-existence of multiple possible reasons, for instance, cerebral infection itself can simultaneously lead to brain damage and hemorrhage by invading blood vessels, and some antibiotics utilized to combat infection may also induce seizures. Based on this fact, investigations into the interaction between varieties of factors can be strengthened. In addition, a small number of patients with unknown etiology might be related to immune encephalitis caused by cGVHD, deeper studies about immune mechanism seem to be promising. Management and prognosis is determined by whether seizures are systemic and usually reversible, such as derangement (e.g., hyponatremia, drug toxicity) or a structural CNS disorder. In summary, clinicians should enhance the understanding of convulsions during the process of HSCT. A close multidisciplinary collaboration between hematologists, neurologists, and radiologists is significant to achieve early diagnosis and timely treatment, thereby ensuring optimal care of such sufferers, reducing mortality, and improving their clinical outcomes.

\section{AUTHOR CONTRIBUTIONS}

All authors contributed to the design, writing, critical revision of this review, and approved the final version of the manuscript.
6. Siegal D, Keller A, Xu W, Bhuta S, Kim DH, Kuruvilla J, et al. Central nervous system complications after allogeneic hematopoietic stem cell transplantation: incidence, manifestations, and clinical significance. Biol Blood Marrow Transplant. (2007) 13:1369-79. doi: 10.1016/j.bbmt.2007.07.013

7. Levine DS, Navarro OM, Chaudry G, Doyle JJ, Blaser SI. Imaging the complications of bone marrow transplantation in children. Radiographics. (2007) 27:307-24. doi: 10.1148/rg.272065088

8. Sostak P, Padovan CS, Yousry TA, Ledderose G, Kolb HJ, Straube A. Prospective evaluation of neurological complications after allogeneic bone marrow transplantation. Neurology. (2003) 60:842-8. doi: 10.1212/01.WNL.0000046522.38465.79

9. Dowling MR, Li S, Dey BR, McAfee SL, Hock HR, Spitzer TR, et al. Neurologic complications after allogeneic hematopoietic stem cell transplantation: risk factors and impact. Bone Marrow Transplant. (2018) 53:199-206. doi: 10.1038/bmt.2017.239

10. Zhang XH, Xu LP, Liu DH, Chen $\mathrm{H}$, Han W, Chen YH, et al. Epileptic seizures in patients following allogeneic hematopoietic stem cell transplantation: a retrospective analysis of incidence, risk factors, and survival rates. Clin Transplant. (2013) 27:80-9. doi: 10.1111/ctr.12000

11. Zivkovic SA, Abdel-Hamid H. Neurologic manifestations of transplant complications. Neurol Clin. (2010) 28:235-51. doi: 10.1016/j.ncl.2009.09.011

12. Cordelli DM, Masetti R, Zama D, Gueraldi D, Rondelli R, Cottone $\mathrm{C}$, et al. Etiology, characteristics and outcome of seizures after 
pediatric hematopoietic stem cell transplantation. Seizure. 23:140-5. doi: 10.1016/j.seizure.2013.11.003

13. Hassan M, Ehrsson H, Smedmyr B, Totterman T, Wallin I, Oberg G, et al. Cerebrospinal fluid and plasma concentrations of busulfan during high-dose therapy. Bone Marrow Transplant. (1989) 4:113-4.

14. Tesfaye H, Branova R, Klapkova E, Prusa R, Janeckova D, Riha P, et al. The importance of therapeutic drug monitoring (TDM) for parenteral busulfan dosing in conditioning regimen for hematopoietic stem cell transplantation (HSCT) in children. Ann Trans. (2014) 19:21424. doi: 10.12659/AOT.889933

15. Santos GW. Busulfan $(\mathrm{Bu})$ and cyclophosphamide (Cy) for marrow transplantation. Bone Marrow Transplant. (1989) 4 (Suppl. 1):236-9.

16. Eberly AL, Anderson GD, Bubalo JS, McCune JS. Optimal prevention of seizures induced by high-dose busulfan. Pharmacotherapy. (2008) 28:150210. doi: 10.1592/phco.28.12.1502

17. La Morgia C, Mondini S, Guarino M, Bonifazi F, Cirignotta F. Busulfan neurotoxicity and EEG abnormalities: a case report. Neurol Sci. (2004) 25:95-7. doi: 10.1007/s10072-004-0237-0

18. Kobayashi R, Watanabe N, Iguchi A, Cho Y, Yoshida M, Arioka H, et al. Electroencephalogram abnormality and high-dose busulfan in conditioning regimens for stem cell transplantation. Bone Marrow Transplant. (1998) 21:217-20. doi: 10.1038/sj.bmt.1701076

19. Akiyama K, Kume T, Fukaya M, Shiki I, Enami T, Tatara R, et al. Comparison of levetiracetam with phenytoin for the prevention of intravenous busulfaninduced seizures in hematopoietic cell transplantation recipients. Cancer Chemother Pharmacol. (2018) 82:717-21. doi: 10.1007/s00280-018-3659-8

20. Caselli D, Rosati A, Faraci M, Podda M, Ripaldi M, Longoni D, et al. Risk of seizures in children receiving busulphan-containing regimens for stem cell transplantation. Biol Blood Marrow Transplant. (2014) 20:2825. doi: 10.1016/j.bbmt.2013.10.028

21. Nakashima T, Tanaka T, Koido K, Nishibuchi Y, Hashimoto H, Ito A, et al. Comparison of valproate and levetiracetam for the prevention of busulfaninduced seizures in hematopoietic stem cell transplantation. Int J Hematol. (2019) 109:694-9. doi: 10.1007/s12185-019-02637-7

22. McCune JS, Wang T, Bo-Subait K, Aljurf M, Beitinjaneh A, Bubalo J, et al. Association of antiepileptic medications with outcomes after allogeneic hematopoietic cell transplantation with busulfan/cyclophosphamide conditioning. Biol Blood Marrow Transplant. (2019) 25:1424-31. doi: 10.1016/j.bbmt.2019.03.001

23. Chan KW, Mullen CA, Worth LL, Choroszy M, Koontz S, Tran $H$, et al. Lorazepam for seizure prophylaxis during highdose busulfan administration. Bone Marrow Transplant. (2002) 29:963-5. doi: 10.1038/sj.bmt.1703593

24. Diaz-Carrasco MS, Olmos R, Blanquer M, Velasco J, Sanchez-Salinas A, Moraleda JM. Clonazepam for seizure prophylaxis in adult patients treated with high dose busulfan. Int J Clin Pharm. (2013) 35:33943. doi: 10.1007/s11096-013-9768-x

25. Floeter AE, McCune JS. Levetiracetam for the prevention of busulfaninduced seizures in pediatric hematopoietic cell transplantation recipients. J Oncol Pharm Pract. (2017) 23:344-9. doi: 10.1177/1078155216651128

26. Chaguaceda C, Aguilera-Jiménez V, Gutierrez G, Roura J, Riu G. Oral levetiracetam for prevention of busulfan-induced seizures in adult hematopoietic cell transplant. Int J Clin Pharm. (2020) 42:351-4. doi: 10.1007/s11096-020-00977-7

27. Zhang W, Egashira N, Masuda S. Recent topics on the mechanisms of immunosuppressive therapy-related neurotoxicities. Int J Mol Sci. (2019) 20:3210. doi: 10.3390/ijms20133210

28. Han LJ, Dong XJ, Jiao XL, Wang XJ, Yuan XG, Ma HX, et al. Analysis of the etiology of epilepsy after allogeneic hematopoietic stem cell transplantation. J Clin Hematol. (2013) 26:602-5. doi: 10.13201/j.issn.1004-2806.2013.05.025

29. Trullemans F, Grignard F, Van Camp B, Schots R. Clinical findings and magnetic resonance imaging in severe cyclosporine-related neurotoxicity after allogeneic bone marrow transplantation. Eur J Haematol. (2001) 67:949. doi: 10.1034/j.1600-0609.2001.t01-1-00440.x

30. Kochi S, Takanaga H, Matsuo H, Ohtani H, Naito M, Tsuruo $\mathrm{T}$, et al. Induction of apoptosis in mouse brain capillary endothelial cells by cyclosporin a and tacrolimus. Life Sci. (2000) 66:2255-60. doi: 10.1016/S0024-3205(00)00554-3
31. Chen S, Hu J, Xu L, Brandon D, Yu J, Zhang J. Posterior reversible encephalopathy syndrome after transplantation: a review. Mol Neurobiol. (2016) 53:6897-909. doi: 10.1007/s12035-015-9560-0

32. Dohgu S, Yamauchi A, Nakagawa S, Takata F, Kai M, Egawa T, et al. Nitric oxide mediates cyclosporine-induced impairment of the blood-brain barrier in cocultures of mouse brain endothelial cells and rat astrocytes. Eur J Pharmacol. (2004) 505:51-9. doi: 10.1016/j.ejphar.2004.10.027

33. Wijdicks EF. Neurotoxicity of immunosuppressive drugs. Liver Transplant. (2001) 7:937-42. doi: 10.1053/jlts.2001.27475

34. Shuto H, Kataoka Y, Fujisaki K, Nakao T, Sueyasu M, Miura I, et al. Inhibition of GABA system involved in cyclosporine-induced convulsions. Life Sci. (1999) 65:879-87. doi: 10.1016/S0024-3205(99)00318-5

35. Tominaga K, Kai M, Yamauchi A, Dohgu S, Toda K, Oishi R, et al. Subchronic treatment with cyclosporin A decreases the binding properties of the GABAA receptor in ovariectomized rats. Life Sci. (2002) 72:42530. doi: 10.1016/S0024-3205(02)02272-5

36. Klawitter J, Gottschalk S, Hainz C, Leibfritz D, Christians U, Serkova NJ. Immunosuppressant neurotoxicity in rat brain models: oxidative stress and cellular metabolism. Chem Res Toxicol. (2010) 23:60819. doi: 10.1021/tx900351q

37. Mun KC, Lee KT, Choi HJ, Jin KB, Han SY, Park SB, et al. Effects of cyclosporine on the production of the reactive oxygen species in the glial cells. Transplant Proc. (2008) 40:2742-3. doi: 10.1016/j.transproceed.2008.08.007

38. Jin KB, Choi HJ, Kim HT, Hwang EA, Suh SI, Han SY, et al. The production of reactive oxygen species in tacrolimus-treated glial cells. Transplant Proc. (2008) 40:2680-1. doi: 10.1016/j.transproceed.2008.08.033

39. Baumgartel K, Mansuy IM. Neural functions of calcineurin in synaptic plasticity and memory. Learn Mem. (2012) 19:37584. doi: $10.1101 / \mathrm{lm} .027201 .112$

40. Daoud D, Scheld HH, Speckmann EJ, Gorji A. Rapamycin: brain excitability studied in vitro. Epilepsia. (2007) 48:8346. doi: 10.1111/j.1528-1167.2006.00976.x

41. Wong M, Yamada KA. Cyclosporine induces epileptiform activity in an in vitro seizure model. Epilepsia. (2000) 41:2716. doi: 10.1111/j.1528-1157.2000.tb00155.x

42. Grioni D, Pavan F, Prunotto G, Canonico F, Grandi C, Rovelli A. Should posterior reversible encephalopathy syndrome be mainly considered an epileptic disorder? Results of a sequential neurophysiological study in a pediatric cohort. Neuropediatrics. (2017) 48:72-8. doi: 10.1055/s-0037-1598251

43. Apuri S, Carlin K, Bass E, Nguyen PT, Greene JN. Tacrolimus associated posterior reversible encephalopathy syndrome - a case series and review. Mediter J Hematol Infect Dis. (2014) 6:e2014014. doi: 10.4084/mjhid.2014.014

44. Fujisaki Y, Yamauchi A, Dohgu S, Sunada K, Yamaguchi C, Oishi $\mathrm{R}$, et al. Cyclosporine A-increased nitric oxide production in the rat dorsal hippocampus mediates convulsions. Life Sci. (2002) 72:54956. doi: 10.1016/S0024-3205(02)02250-6

45. Yanagimachi M, Naruto T, Tanoshima R, Kato H, Yokosuka T, Kajiwara R, et al. Influence of CYP3A5 and ABCB1 gene polymorphisms on calcineurin inhibitor-related neurotoxicity after hematopoietic stem cell transplantation. Clin Transplant. (2010) 24:855-61. doi: 10.1111/j.1399-0012.2009.01181.x

46. Schultz L, Zurich MG, Culot M, da Costa A, Landry C, Bellwon $\mathrm{P}$, et al. Evaluation of drug-induced neurotoxicity based on metabolomics, proteomics and electrical activity measurements in complementary CNS in vitro models. Toxicol In Vitro. (2015) 30:138-65. doi: 10.1016/j.tiv.2015.05.016

47. Jung S, Yang $\mathrm{H}$, Kim BS, Chu K, Lee SK, Jeon D. The immunosuppressant cyclosporin A inhibits recurrent seizures in an experimental model of temporal lobe epilepsy. Neurosci Lett. (2012) 529:133-8. doi: 10.1016/j.neulet.2012.08.087

48. Wen $\mathrm{Y}, \mathrm{Fu} \mathrm{P}, \mathrm{Wu} \mathrm{K}, \mathrm{Si} \mathrm{K}$, Xie $\mathrm{Y}, \mathrm{Dan} \mathrm{W}$, et al. Inhibition of Calcineurin A by FK506 suppresses seizures and reduces the expression of GluN2B in membrane fraction. Neurochem Res. (2017) 42:215466. doi: 10.1007/s11064-017-2221-0

49. Esposito S, Canevini MP, Principi N. Complications associated with antibiotic administration: neurological adverse events and 
interference with antiepileptic drugs. Int J Antimicrob Agents. (2017) 50:1-8. doi: 10.1016/j.ijantimicag.2017.01.027

50. Sutter R, Ruegg S, Tschudin-Sutter S. Seizures as adverse events of antibiotic drugs: a systematic review. Neurology. (2015) 85:133241. doi: 10.1212/WNL.0000000000002023

51. Miller AD, Ball AM, Bookstaver PB, Dornblaser EK, Bennett CL. Epileptogenic potential of carbapenem agents: mechanism of action, seizure rates, and clinical considerations. Pharmacotherapy. (2011) 31:40823. doi: 10.1592/phco.31.4.408

52. Cock HR. Drug-induced status epilepticus. Epilepsy Behav. (2015) 49:7682. doi: 10.1016/j.yebeh.2015.04.034

53. Wanleenuwat P, Suntharampillai N, Iwanowski P. Antibiotic-induced epileptic seizures: mechanisms of action and clinical considerations. Seizure. (2020) 81:167-74. doi: 10.1016/j.seizure.2020.08.012

54. Bacigalupo A, Boyd A, Slipper J, Curtis J, Clissold S. Foscarnet in the management of cytomegalovirus infections in hematopoietic stem cell transplant patients. Expert Rev Antiinfect Ther. (2012) 10:124964. doi: $10.1586 /$ eri.12.115

55. Pejcic A, Jankovic SM, Opancina V, Babic G, Milosavljevic M. Drug-drug interactions in patients receiving hematopoietic stem cell transplantation. Expert Opin Drug Metabol Toxicol. (2019) 15:49-59. doi: 10.1080/17425255.2019.1552256

56. Groll AH, Desai A, Han D, Howieson C, Kato K, Akhtar S, et al. Pharmacokinetic assessment of drug-drug interactions of isavuconazole with the immunosuppressants cyclosporine, mycophenolic acid, prednisolone, sirolimus, and tacrolimus in healthy adults. Clin Pharmacol Drug Dev. (2017) 6:76-85. doi: $10.1002 /$ cpdd.284

57. Caihong Q, Weimin L, Jieming Z. Elevation of blood ciclosporin levels by voriconazole leading to leukoencephalopathy. J Pharmacol Pharmacother. (2013) 4:294-7. doi: 10.4103/0976-500X.119721

58. Shepard PW, St Louis EK. Seizure treatment in transplant patients. Curr Treat Options Neurol. (2012) 14:332-47. doi: 10.1007/s11940-012-0180-y

59. Zhong ZD, Li L, Wu YH, You Y, Li WM, Zou P. Analysis of seizure risk factors after allogeneic hematopoietic stem cell transplantation: a 8 case report and literature review. J Huazhong Univ Sci Technol Med Sci. (2013) 33:656-60. doi: 10.1007/s11596-013-1176-x

60. Nardone R, Brigo F, Trinka E. Acute symptomatic seizures caused by electrolyte disturbances. J Clin Neurol. (2016) 12:21-33. doi: 10.3988/jen.2016.12.1.21

61. Castilla-Guerra L, del Carmen Fernandez-Moreno M, Lopez-Chozas JM, Fernandez-Bolanos R. Electrolytes disturbances and seizures. Epilepsia. (2006) 47:1990-8. doi: 10.1111/j.1528-1167.2006.00861.x

62. Maffini E, Festuccia M, Brunello L, Boccadoro M, Giaccone L, Bruno B. Neurologic complications after allogeneic hematopoietic stem cell transplantation. Biol Blood Marrow Transplant. (2017) 23:388-97. doi: 10.1016/j.bbmt.2016.12.632

63. Hanajiri R, Kobayashi T, Yoshioka K, Watanabe D, Watakabe K, Murata Y, et al. Central nervous system infection following allogeneic hematopoietic stem cell transplantation. Hematol Oncol Stem Cell Ther. (2017) 10:228. doi: 10.1016/j.hemonc.2016.08.008

64. Chaudhary RK, Dhakal P, Aryal A, Bhatt VR. Central nervous system complications after allogeneic hematopoietic stem cell transplantation. Future Oncol. (2017) 13:2297-312. doi: 10.2217/fon-2017-0274

65. Servais S, Lengline E, Porcher R, Carmagnat M, Peffault de Latour R, Robin $\mathrm{M}$, et al. Long-term immune reconstitution and infection burden after mismatched hematopoietic stem cell transplantation. Biol Blood Marrow Transplant. (2014) 20:507-17. doi: 10.1016/j.bbmt.2014.01.001

66. Bonardi M, Turpini E, Sanfilippo G, Mina T, Tolva A, Zappoli Thyrion F. Brain imaging findings and neurologic complications after allogenic hematopoietic stem cell transplantation in children. Radiographics. (2018) 38:1223-38. doi: 10.1148/rg.2018170139

67. Dhar R. Neurologic complications of transplantation. Neurocrit Care. (2018) 28:4-11. doi: 10.1007/s12028-017-0387-6

68. Balaguer Rosello A, Bataller L, Lorenzo I, Jarque I, Salavert M, Gonzalez E, et al. Infections of the central nervous system after unrelated donor umbilical cord blood transplantation or human leukocyte antigen-matched sibling transplantation. Biol Blood Marrow Transplant. (2017) 23:1349. doi: 10.1016/j.bbmt.2016.10.005
69. Syed FI, Couriel DR, Frame D, Srinivasan A. Central nervous system complications of hematopoietic stem cell transplant. Hematol. Oncol. Clin. North Am. (2016) 30:887-98. doi: 10.1016/j.hoc.2016.03.009

70. Dulamea AO, Lupescu IG. Neurological complications of hematopoietic cell transplantation in children and adults. Neural Regen Res. (2018) 13:94554. doi: 10.4103/1673-5374.233431

71. Sonneville R, Magalhaes E, Meyfroidt G. Central nervous system infections in immunocompromised patients. Curr Opin Crit Care. (2017) 23:128-33. doi: 10.1097/MCC.0000000000000397

72. Fujita Y, Rooney CM, Heslop HE. Adoptive cellular immunotherapy for viral diseases. Bone Marrow Transplant. (2008) 41:1938. doi: 10.1038/sj.bmt.1705906

73. Santoro JD, Hemond CC. Human herpesvirus 6 associated post-transplant acute limbic encephalitis: Clinical observations of biomarkers for risk of seizure in a pediatric population. Transplant Infect Dis. (2019) 21:e13003. doi: 10.1111/tid.13003

74. Roseti C, van Vliet EA, Cifelli P, Ruffolo G, Baayen JC, Di Castro MA, et al. GABAA currents are decreased by IL-1beta in epileptogenic tissue of patients with temporal lobe epilepsy: implications for ictogenesis. Neurobiol Dis. (2015) 82:311-20. doi: 10.1016/j.nbd.2015.07.003

75. Zhu G, Okada M, Yoshida S, Mori F, Ueno S, Wakabayashi K, et al. Effects of interleukin-1beta on hippocampal glutamate and GABA releases associated with $\mathrm{Ca} 2+$-induced Ca2+ releasing systems. Epilepsy Res. (2006) 71:107-16. doi: 10.1016/j.eplepsyres.2006.05.017

76. Coplin WM, Cochran MS, Levine SR, Crawford SW. Stroke after bone marrow transplantation: frequency, aetiology and outcome. Brain J Neurol. (2001) 124:1043-51. doi: 10.1093/brain/124.5.1043

77. Lin TA, Gau JP, Liu YC, Ko PS, Wang HY, Chien SH, et al. Cerebrovascular disease after allogeneic hematopoietic stem cell transplantation: incidence, risk, and clinical outcome. Int $J$ Hematol. (2019) 109:584-92. doi: 10.1007/s12185-019-02624-y

78. Zhang XH, Wang QM, Chen H, Chen YH, Han W, Wang FR, et al. Clinical characteristics and risk factors of intracranial hemorrhage in patients following allogeneic hematopoietic stem cell transplantation. Ann Hematol. (2016) 95:1637-43. doi: 10.1007/s00277-016-2767-y

79. Najima Y, Ohashi K, Miyazawa M, Nakano M, Kobayashi T, Yamashita T, et al. Intracranial hemorrhage following allogeneic hematopoietic stem cell transplantation. Am J Hematol. (2009) 84:298-301. doi: 10.1002/ajh.21382

80. Han W, Chen Y, Chen H, Liu D, Xu L, Liu K, et al. Intracranial hemorrhage and mortality in 1461 patients after allogeneic hematopoietic stem cell transplantation for 6-year follow-up: study of 44 cases. Blood. (2013) 122:3322. doi: 10.1182/blood.V122.21.3322.3322

81. Doria JW, Forgacs PB. Incidence, implications, and management of seizures following ischemic and hemorrhagic stroke. Curr Neurol Neurosci Rep. (2019) 19:37. doi: 10.1007/s11910-019-0957-4

82. Lin P, Tian X, Wang X. Seizures after transplantation. Seizure. (2018) 61:17785. doi: 10.1016/j.seizure.2018.08.010

83. Choi CM, Schmaier AH, Snell MR, Lazarus HM. Thrombotic microangiopathy in haematopoietic stem cell transplantation: diagnosis and treatment. Drugs. (2009) 69:18398. doi: 10.2165/00003495-200969020-00004

84. Khosla J, Yeh AC, Spitzer TR, Dey BR. Hematopoietic stem cell transplant-associated thrombotic microangiopathy: current paradigm and novel therapies. Bone Marrow Transplant. (2018) 53:129-37. doi: 10.1038/bmt.2017.207

85. Oshima K, Kanda Y, Yamashita T, Takahashi S, Mori T, Nakaseko C, et al. Central nervous system relapse of leukemia after allogeneic hematopoietic stem cell transplantation. Biol Blood Marrow Transplant. (2008) 14:11007. doi: 10.1016/j.bbmt.2008.07.002

86. Server A, Bargallo N, Floisand Y, Sponheim J, Graus F, Hald JK. Imaging spectrum of central nervous system complications of hematopoietic stem cell and solid organ transplantation. Neuroradiology. (2017) 59:10526. doi: 10.1007/s00234-017-1804-4

87. Grauer O, Wolff D, Bertz H, Greinix H, Kuhl JS, Lawitschka A, et al. Neurological manifestations of chronic graft-versus-host disease after allogeneic haematopoietic stem cell transplantation: report from the consensus conference on clinical practice in chronic graft-versus-host disease. Brain J Neurol. (2010) 133:2852-65. doi: 10.1093/brain/awq245 
88. Saad AG, Alyea EP, 3rd, Wen PY, Degirolami U, Kesari S. Graft-versushost disease of the CNS after allogeneic bone marrow transplantation. J Clin Oncol. (2009) 27:e147-9. doi: 10.1200/JCO.2009.21.7919

89. Sostak P, Padovan CS, Eigenbrod S, Roeber S, Segerer S, Schankin C, et al. Cerebral angiitis in four patients with chronic GVHD. Bone Marrow Transplant. (2010) 45:1181-8. doi: 10.1038/bmt.2009.323

90. Lu JQ, Steve TA, Wheatley M, Gross DW. Immune cell infiltrates in hippocampal sclerosis: correlation with neuronal loss. J Neuropathol Exp Neurol. (2017) 76:206-15. doi: 10.1093/jnen/nlx001

91. Cordelli DM, Masetti R, Bernardi B, Barcia G, Gentile V, Biagi C, et al. Status epilepticus as a main manifestation of posterior reversible encephalopathy syndrome after pediatric hematopoietic stem cell transplantation. Pediatr Blood Cancer. (2012) 58:785-90. doi: 10.1002/pbc.23344

92. Hammerstrom AE, Howell J, Gulbis A, Rondon G, Champlin RE, Popat U. Tacrolimus-associated posterior reversible encephalopathy syndrome in hematopoietic allogeneic stem cell transplantation. Am J Hematol. (2013) 88:301-5. doi: 10.1002/ajh.23402

93. Zama D, Masetti R, Cordelli DM, Vendemini F, Giordano L, Milito G, et al. Risk factor analysis of posterior reversible encephalopathy syndrome after allogeneic hematopoietic SCT in children. Bone Marrow Transplant. (2014) 49:1538-40. doi: 10.1038/bmt.2014.182

94. Bartynski WS. Posterior reversible encephalopathy syndrome, part 1: fundamental imaging and clinical features. AJNR Am J Neuroradiol. (2008) 29:1036-42. doi: 10.3174/ajnr.A0928

95. Balaguer-Rosello A, Bataller L, Pinana JL, Montoro J, Lorenzo I, Villalba A, et al. Noninfectious neurologic complications after allogeneic hematopoietic stem cell transplantation. Biol Blood Marrow Transplant. (2019) 25:18181824. doi: 10.1016/j.bbmt.2019.05.024

96. Vesole AS, Nagahama Y, Granner MA, Howard MA, Kawasaki H, Dlouhy BJ. Drug-resistant epilepsy development following stem cell transplant and cyclosporine neurotoxicity induced seizures: case report in an adult and analysis of reported cases in the literature. Epilepsy Behav Case Rep. (2018) 10:8-13. doi: 10.1016/j.ebcr.2018.01.002

97. Dhar R. Neurologic complications of transplantation. Handbook Clin Neurol. (2017) 141:545-72. doi: 10.1016/B978-0-444-63599-0.00030-2

98. Kapoor R, Simalti A, Kumar R, Yanamandra U, Das S, Singh J, et al. PRES in pediatric HSCT: a single-center experience. J Pediatr Hematol Oncol. (2018) 40:433-7. doi: 10.1097/MPH.0000000000001190
99. Masetti R, Cordelli DM, Zama D, Vendemini F, Biagi C, Franzoni E, et al. PRES in children undergoing hematopoietic stem cell or solid organ transplantation. Pediatrics. (2015) 135:890-901. doi: 10.1542/peds.2014-2325

100. Ohsaka M, Houkin K, Takigami M, Koyanagi I. Acute necrotizing encephalopathy associated with human herpesvirus-6 infection. Pediatr Neurol. (2006) 34:160-3. doi: 10.1016/j.pediatrneurol.2005.07.007

101. Yong-Gang X, Ming-Zhe W, Jin-Yan Z, Zhi-Hai P, Jun-Ming X. Combination of $\mathrm{N}$-(3'4'-dimethoxycinnamoyl) anthranilic acid with cyclosporin A treatment preserves immunosuppressive effect and reduces the side effect of cyclosporin A in rat. Eur J Pharmacol. (2014) 728:1623. doi: 10.1016/j.ejphar.2014.01.055

102. Ide $\mathrm{K}$, Ohdan $\mathrm{H}$, Tahara $\mathrm{H}$, Ishiyama $\mathrm{K}$, Shishida $\mathrm{M}$, Irei $\mathrm{T}$, et al. Possible therapeutic effect of lipid supplementation on neurological complications in liver transplant recipients. Transpl Int. (2007) 20:6325. doi: 10.1111/j.1432-2277.2007.00487.x

103. Chabolla DR, Wszolek ZK. Pharmacologic management of seizures in organ transplant. Neurology. (2006) $67 \quad(12$ Suppl. 4):S34-8. doi: 10.1212/WNL.67.12_suppl_4.S34

104. St Louis EK, Gidal BE, Henry TR, Kaydanova Y, Krumholz A, McCabe $\mathrm{PH}$, et al. Conversions between monotherapies in epilepsy: expert consensus. Epilepsy Behav. (2007) 11:222-34. doi: 10.1016/j.yebeh.2007. 04.007

105. Peyrl A, Weichert N, Kühl J-S, Ebell W, Hernáiz Driever P. Levetiracetam as a possible cause of secondary graft failure after allogenic hematopoietic stem cell transplantation. Eur J Paediatr Neurol. (2015) 19:75-7. doi: 10.1016/j.ejpn.2014.10.004

Conflict of Interest: The authors declare that the research was conducted in the absence of any commercial or financial relationships that could be construed as a potential conflict of interest.

Copyright (c) 2021 Wang, Zhao and Gao. This is an open-access article distributed under the terms of the Creative Commons Attribution License (CC BY). The use, distribution or reproduction in other forums is permitted, provided the original author(s) and the copyright owner(s) are credited and that the original publication in this journal is cited, in accordance with accepted academic practice. No use, distribution or reproduction is permitted which does not comply with these terms. 